\title{
Progress in studies of natural gas conversion in China*
}

\author{
Yu Changchun** and Shen Shikong \\ Key Laboratory of Catalysis under CNPC, China University of Petroleum, Beijing 102249, China
}

\begin{abstract}
Progress in natural gas conversion in China is presented in this paper, including processes of natural gas to synthesis gas (syngas), syngas to liquid hydrocarbons, oxygenates synthesis, methanol to olefins (MTO), methane to aromatics and oxidative coupling of methane (OCM).
\end{abstract}

Key words: Methane, natural gas conversion, GTL, synthesis gas, hydrocarbons, alcohols, olefins, methanol, dimethyl ether

\section{Introduction}

According to the data from China State Statistics Bureau, the output of natural gas in China was less than $1 \times 10^{10} \mathrm{~m}^{3}$ before 1995 , of which about $45 \%$ was used as chemical industry feedstock. In 2004, the output of natural gas in China reached $4.07 \times 10^{10} \mathrm{~m}^{3}$, of which the commercial sales volume was $3 \times 10^{10} \mathrm{~m}^{3}$, while the natural gas used as chemical industry feedstock decreased to $35 \%$, but the absolute quantity was 2.3 times higher than that of 1995. Up to date, the natural gas used as chemical industry feedstock in China for ammonia synthesis accounts for $60 \%$, for methanol synthesis accounts for $30 \%$, for acetylene and all the other products accounts for $10 \%$ (Kong and $\mathrm{Wu}, 2004$ ).

Up to 2005 , China had only shared $1.3 \%$ of the world total natural gas resources, and the corresponding price was relative high, which is unfavorable for the development of natural gas chemical industry in China. However, globalization is a trend in the future and the neighboring countries of China, countries in Middle East and Australia have abundant natural gas resources, which is favorable for China to utilize these foreign natural gas resources. From the viewpoint of optimal utilization of natural gas resources, the chemical industry in China has quite a large potential size in the utilization of natural gas. Chemical conversion and utilization of natural gas has always been put in an important position in China, and a lot of progress has been made. Processes with independent intellectual property rights, including MTO and coal-based synthesized fuel were developed and achieved pilot plant demonstration, providing strong technical support for sustainable development of natural gas chemical industry in China.

Because of the shortage of petroleum resources and more strict environmental regulations, the conversion of natural gas to liquids (GTL), natural gas to olefins (GTO), natural gas

\footnotetext{
* Supported by the National Natural Science Foundation of China (20490201, 20306016)

** Corresponding author. e-mail: yucc@cup.edu.cn

Received March 11, 2007
}

to oxygenate and natural gas to hydrogen has attracted more attention in China and worldwide.

Research and development of natural gas conversion in China are presented in this paper, and suggestions on utilization of natural gas are made for natural gas chemical industry.

\section{Conversion of natural gas to syngas}

Catalytic partial oxidation (CPO) of natural gas to syngas is a mild exothermic reaction $\left(\Delta \mathrm{H}^{\circ}=-36 \mathrm{~kJ} / \mathrm{mol}\right)$. Worldwide researchers have carried out lots of studies on CPO process since 1990 (Ashcroft et al, 1990; Hickman and Schmidt, 1993; Lu et al, 1998; Zhang et al, 2000; Li et al, 2001; Yang et al, 2002). The results indicated that both noble metal catalysts and nickel catalysts have very high activity for CPO reaction, and alkaline earth metal oxide and rare earth metal oxide promoters can inhibit carbon deposition reactions over nickel catalysts. Because of very high reaction rate of CPO, controlling reaction temperature to avoid runaway of the catalyst bed temperature is the key to scale up of CPO reactor (Shen et al, 2001). Currently, syngas production based on CPO is still in the phase of laboratory research with only one exception of pilot plant test of ExxonMobil's fixed fluidized bed CPO process (Eisenberg et al, 1999).

Highly active anti-carbon deposition catalyst is most important for the CPO process. The $\mathrm{La}_{2} \mathrm{O}_{3}-\mathrm{Ni} / \mathrm{MgAlO}_{3}$ $\mathrm{Al}_{2} \mathrm{O}_{3}$ catalyst developed by Lu et al (1998) is a nickel-based highly active anti-carbon deposition CPO catalyst. For the catalyst, an $\mathrm{MgAl}_{2} \mathrm{O}_{4}$ spinel membrane formed on the surface of $\mathrm{Al}_{2} \mathrm{O}_{3}$ support can prevent the reaction of high temperature solid phase between nickel and alumina, thus avoiding the formation of $\mathrm{NiAl}_{2} \mathrm{O}_{4}$ spinel phase, which is an inactive phase for $\mathrm{CPO}$ reaction and will result in catalyst deactivation. The catalyst promoted by the strong basic $\mathrm{La}_{2} \mathrm{O}_{3}$ promoter can weaken the metallicity of nickel and slightly decrease the activity for methane dissociation on the catalyst. By these promoters' modification, once methane dissociates over the catalyst, surface carbon species can react with surface oxygen species and form $\mathrm{CO}$, and accordingly surface carbon 
deposition is avoided.

Although CPO is a mild exothermic reaction, very high gas hourly space velocity would cause a large quantity of heat release in catalyst bed in a short time period, consequently resulting in the formation of hot spot and temperature runaway. In addition, the feedstock methane to oxygen molar ratio is $2: 1$, which is in the range of upper and lower limits of explosion of $\mathrm{CH}_{4} / \mathrm{O}_{2}$ mixture, and safe operation of CPO process is one of the key technologies for CPO commercialization. Lu et al (1998) developed a new technology, which is a combination of low temperature catalytic combustion and catalytic partial oxidation. It includes a serially connected cascade of two fixed bed reactors. The first one is a catalytic combustion reactor, in which a perovskite type combustion catalyst $\mathrm{La}_{0.7} \mathrm{Ca}_{0.3} \mathrm{Fe}_{0.3} \mathrm{Mn}_{0.7} \mathrm{O}_{3}$ is packed. All the methane and $25 \%$ of the total oxygen is pre-heated to $450-500{ }^{\circ} \mathrm{C}$ and fed into the first reactor. $6 \%-7 \%$ of methane is deeply oxidized into $\mathrm{CO}_{2}$ and $\mathrm{H}_{2} \mathrm{O}$, meanwhile, the feedstock is autothermally heated to $800-900{ }^{\circ} \mathrm{C}$. The effluent gas of the first reactor together with the rest $75 \%$ of the total oxygen is fed into the second reactor, in which $\mathrm{CH}_{4}$ reacts with $\mathrm{O}_{2}, \mathrm{CO}_{2}$ and $\mathrm{H}_{2} \mathrm{O}$ over a multifunctional catalyst $\mathrm{La}_{2} \mathrm{O}_{3}-\mathrm{Ni} / \mathrm{MgAlO}_{3}-\mathrm{Al}_{2} \mathrm{O}_{3}$. In the second reactor, the heat released by exothermic $\mathrm{CPO}$ reaction was balanced by the endothermic steam reforming reaction and dry reforming reaction. In this way, an adiabatic and constant temperature operation can be expected.

The results of the two-stage partial oxidation in syngas production show that under the conditions of the first reactor inlet temperature of $400{ }^{\circ} \mathrm{C}$, the second reactor temperature of $950{ }^{\circ} \mathrm{C}$, feedstock composition of $\mathrm{CH}_{4}: \mathrm{O}_{2}(1 \mathrm{st}): \mathrm{O}_{2}(2 \mathrm{nd})=8: 1: 3$ (molar ratio), the conversion of methane is $83 \%$, the $\mathrm{CO}$ and $\mathrm{H}_{2}$ selectivities are $92 \%$ and $91 \%$, respectively. In a 300 -hour stability test, the conversion of methane of $84 \%$ and syngas selectivity of $94 \%$ are quite close to the thermodynamics equilibrium under the same conditions. The two-stage CPO process is now in the phase of multikilogram catalyst-based bench scale test.

Yang et al (2002) developed a hydrogen production process based on CPO technology. A 1000-hour stability test was carried out at Daqing Refining and Chemical Company using $500 \mathrm{~g}$ impregnated $\mathrm{Ni}-\mathrm{La} / \mathrm{Al}_{2} \mathrm{O}_{3}$ catalyst at a pressure of $0.8 \mathrm{MPa}$ and $\mathrm{CH}_{4}: \mathrm{Air}: \mathrm{H}_{2} \mathrm{O}=1: 2.4: 2$ (molar ratio). The exit gas composition was $44.4 \% \mathrm{H}_{2}, 36.4 \% \mathrm{~N}_{2}, 9.6 \% \mathrm{CO}, 1.0 \%$ $\mathrm{CH}_{4}$ and $8.6 \% \mathrm{CO}_{2}$ (volume percentage) at a gas hourly space velocity of $6000 \mathrm{~h}^{-1}$. The results showed that the catalyst had good activity, selectivity and stability, and no hot spot was observed in the reactor during the test period.

With regard to feedstock composition and product composition, CPO process and autothermal reforming (ATR) process has no distinct difference. As the reactor effluent gas composition is nearly in thermodynamics equilibrium, the product gas compositions of CPO and ATR are quite close under similar operation conditions. For CPO process, the auto-ignition temperature of feedstock $\mathrm{CH}_{4}: \mathrm{O}_{2}=2: 1$ (molar ratio) is $250{ }^{\circ} \mathrm{C}$, the pre-heat temperature of feedstock can not be higher than its auto-ignition temperature. While, for ATR process, natural gas and oxygen are fed into reactor separately, so the feedstock can be pre-heated up to $650{ }^{\circ} \mathrm{C}$, which is far higher than that of $\mathrm{CPO}$ process. In addition, the temperature of exit gas of ATR process is about $1050{ }^{\circ} \mathrm{C}$. In $\mathrm{CPO}$ process, as the feedstock temperature is limited by its auto-ignition temperature, in order to reach a high exit gas temperature of ca. $1050{ }^{\circ} \mathrm{C}$, a small fraction of natural gas and oxygen are used as fuel to be burnt to heat the reaction gas. By this way, the natural gas and oxygen consumption in $\mathrm{CPO}$ process is $7 \%$ and $18 \%$, respectively, higher than that in ATR process (Bakkerud and Gol, 2004). Whether CPO or ATR process is more advanced needs further research.

In ATR process, oxygen production cost accounts for $40 \%$ of operation cost. In order to cut down the oxygen production cost, ion transportation membrane (ITM) based syngas production technology has been studied and developed by 9 research organizations and universities supported by the US Department of Energy (DOE) since 1997 (Chen et al, 2004). In the ITM process, oxygen in air obtains electrons on one side of the membrane and forms oxygen anions, and the oxygen anions are transported from one side to the other side and react with natural gas to produce syngas. At the same time, the electrons of oxygen anions are released, thus the ITM cycle can carry on repeatedly. Many investigations of the ITM process were conducted (Mazanec et al, 2001; Wang et al, 2003), the high-temperature stability of ITM membrane and scale up of the membranes reactor are still problems and need further studies.

A novel route for syngas production using lattice oxygen of composite oxide instead of molecular oxygen was developed ( $\mathrm{Li}$ et al, 2004). In this route, the composite oxide acts as an oxygen carrier and syngas is produced by using a reduction-oxidation cycle. In the reduction step, the composite oxide loses its lattice oxygen, which reacts with methane to produce syngas, and then in the following oxidation step, the composite oxide that has lost lattice oxygen contacts with air and captures oxygen from air, and converts the oxygen to its lattice oxygen. A perovskite-type oxide, $\mathrm{La}_{1-\mathrm{x}} \mathrm{Sr}_{\mathrm{x}} \mathrm{FeO}_{3}$, is used in air-methane periodically switched reactions to produce syngas, and syngas selectivity is more than $90 \%$.

\section{Conversion of natural gas to liquids (GTL)}

Since the 1980s, Shanxi Institute of Coal Chemistry of Chinese Academy of Sciences (CAS) has carried out a research on coal-based syngas and iron-based catalyst using Fischer-Tropsch synthesis (FTS) process. In February 2006, a $160 \mathrm{kt} / \mathrm{a}$ coal-based FTS plant was built at Changzhi, Shanxi province. In the latest decade, Shanxi Institute of Coal Chemistry of CAS (Chen and Sun, 2004), Dalian Institute of Chemical Physics of CAS and China University of Petroleum (Beijing) have carried out research on natural gas-based syngas and cobalt-based catalyst FTS, and a onetube fixed-bed reactor FTS has been developed by the three organizations.

\section{Synthesis of methanol and other alcohols}

In the traditional methanol synthesis process, a large amount of unconverted syngas is recycled. In order to avoid this disadvantage, a new methanol synthesis technology under supercritical condition was developed by the Shanxi Institute 
of Coal Chemistry of CAS (Wei et al, 1999). In the methanol synthesis process, a supercritical solvent, for example $\mathrm{n}$-hexane or n-heptane, is added, thus the formed methanol can be successively transferred from gas phase to supercritical phase. By this way, the thermodynamics equilibrium in the methanol synthesis process is broken, and the $\mathrm{CO}$ conversion reaches $90 \%$. Because a large amount of supercritical solvent is added to the process, energy consumption and supercritical solvent consumption increase. Reducing the negative effects caused by the use of supercritical solvent is the critical issue of this process.

Synthesis of ethanol and higher alcohols mixture also attract researchers' attention. Dalian Institute of Chemical Physics of CAS has successfully developed a rhodium-based catalyst for ethanol synthesis, in which the content of rhodium is less than $1 \mathrm{wt} \%$, and a 1000 -hour continuous pilot-scale test had been carried out. The results show that the catalyst has good stability, and the ethanol selectivity is $90 \%$ after hydrogenation of the product. Ethanol and ethyl acetate can be prepared with high-selectivity by changing catalyst components and operation conditions. This process shows high potential for future applications (Yin et al, 2003a; 2003b; Yin, 2003).

A catalyst, Mn-Ni-K-MoS 2 , has been developed by the Shanxi Institute of Coal Chemistry of CAS for $\mathrm{C}_{2+}$ higher alcohols synthesis, and a 1000-hour bench-scale test has been performed (Qi et al, 2003). The results indicate that the catalyst has good activity, and the $\mathrm{C}_{2+}$ alcohols selectivity is $40 \%-50 \%$. The results have been repeated in a pilot-scale test of single tube reactor.

\section{Conversion of methanol to olefins (MTO)}

In the MTO process, dimethyl ether (DME) is the intermediate of methanol dehydration to olefins. Based on this knowledge, Dalian Institute of Chemical Physics of CAS has proposed an olefins synthesis route, in which olefins are synthesized from syngas via methanol or DME. For coalbased syngas, the $\mathrm{H}_{2} / \mathrm{CO}$ molar ratio is approximately 1 , which is the stoichiometric ratio of one-step DME synthesis from syngas. Thus, the conversion of one-step DME synthesis from syngas is significantly higher than that of methanol synthesis using coal-based syngas as feedstock, in addition, the capital cost and operation cost of DME to olefins (DTO) process can be cut down compared with MTO process.

Investigations of MTO and DTO processes have been conducted by Dalian Institute of Chemical Physics of CAS since 1990 (Liu et al, 2000). New silicoaluminophosphate (SAPO) and metal silicoaluminophosphate (MeAPSO) molecular sieves with a small pore size have been synthesized by using cheap raw materials and metal hetero-atom modification of SAPO-34. Furthermore, microspherical catalyst preparation technology by the spray method has been developed. The catalyst prepared by this technology can satisfy the requirement of industrial fluidized-bed reactors. The methanol conversion is $100 \%$, and the total selectivity of ethylene and propene is higher than $90 \%$. In addition, the ethylene to propene ratio is adjustable in a certain range. Dalian Institute of Chemical Physics of CAS, owner of independent intellectual property rights, has collaborated with
Shaanxi Provincial Investment Corporation and Luoyang Petrochemical Engineering Corporation to build a $10 \mathrm{kt} / \mathrm{a}$ scale MTO pilot plant in Shaanxi province since August 2004. The plant was put into operation in February 2006.

Gas to olefins (GTO) process is quite important for the development of petrochemical industry in the areas, which have abundant natural gas resources but are short of oil. Both Southwest Petroleum Administration of China National Petroleum Corporation (CNPC) and Daqing Refining and Chemical Company of CNPC have planned their petrochemical development program of GTO. Conceptual design of GTO by Daqing Refining and Chemical Company of CNPC shows good economic benefit at a price of natural gas below RMB $¥ 1 / \mathrm{m}^{3}$.

\section{Syngas to DME}

DME is one of the important derivatives of methanol and can be prepared by dehydration of methanol. The physical properties of DME are similar to liquid petroleum gas (LPG), so DME is considered as synthesized LPG. DME has a high cetane number and good compression ignition performance, and it is easily converted to hydrogen by reforming reaction. Lots of research had been carried out by Amoco and Haldor Topsøe for DME synthesis and application in 1990s (Fleisch and Sills, 2004).

DME can also be synthesized from syngas directly. In this way, methanol synthesis and dehydration take place simultaneously in one reactor, which contains both methanol synthesis catalyst $\mathrm{Cu}-\mathrm{Zn}-\mathrm{Al}_{2} \mathrm{O}_{3}$ and acidic methanol dehydration catalyst (Wang, 2003). Because of high equilibrium conversion of syngas to DME, the singlepass syngas conversion can reach $70 \%$ by this route, which is significantly higher than that of methanol synthesis process. In this process, catalyst $\mathrm{Cu}-\mathrm{Zn}-\mathrm{Al}_{2} \mathrm{O}_{3}$ also catalyzes water gas shift reaction.

One-step DME synthesis reaction:

$$
3 \mathrm{CO}+3 \mathrm{H}_{2} \rightarrow \mathrm{CH}_{3} \mathrm{OCH}_{3}+\mathrm{CO}_{2}
$$

Two-step DME synthesis reaction:

$$
2 \mathrm{CO}+4 \mathrm{H}_{2} \rightarrow 2 \mathrm{CH}_{3} \mathrm{OH} \rightarrow \mathrm{CH}_{3} \mathrm{OCH}_{3}+\mathrm{H}_{2} \mathrm{O}
$$

The two DME synthesis routes above show that the twostep DME synthesis is more suitable for natural gas-based syngas $\left(\mathrm{H}_{2} / \mathrm{CO}\right.$ molar ratio of 2$)$ as feedstock, while one-step DME synthesis is more suitable for coal-based syngas $\left(\mathrm{H}_{2} /\right.$ $\mathrm{CO}$ molar ratio of 1) as feedstock. The cost of one-step DME synthesis is lower than that of two-step DME synthesis, and one-step DME synthesis in slurry-bed reactor is the direction of the process. One-step DME synthesis has been studied by Tsinghua University (Wang et al, 2004), Shanxi Institute of Coal Chemistry of CAS (Xie et al, 2004), and Daqing Refining and Chemical Company of CNPC (Xu et al, 2004a).

\section{Methane direct conversion}

Methane dehydrogenation and aromatization (MDA) is a new process developed by Dalian Institute of Chemical Physics of CAS (Wang et al, 1993). Methane can be 
converted to benzene and hydrogen with high selectivity by using Mo-modified ZSM-5 molecular sieve as catalyst at $700{ }^{\circ} \mathrm{C}$. Hydrogen is a future clean fuel, and benzene is an important petrochemical feedstock. This reaction has attracted lots of attention. Research shows that a small amount of naphthalene and $\mathrm{C}_{2}$ hydrocarbons are obtained besides benzene in the product (Shu and Ichikawa, 2001; Huang et al, 2004; Xu et al, 2003). The catalyst deactivates easily, and the deactivated catalyst is hard to return to its original activity after regeneration. Mo, Re and $\mathrm{W}$ supported on HZSM-5, HMCM-22 and HZSM-11 molecular sieves shows good catalytic performance. In MDA process, the catalyst deactivation caused by carbon deposition is the key problem to be solved. Studies on theory and experiments conducted over Mo/HZSM-5 by Xu et al (2003) show that the valence and position of atom Mo, and the channel structure and Brönsted acid sites distribution of the molecular sieve, are the key factors for catalyst performance. The results of in situ MAS NMR prove that carbon deposition occurs on Brönsted acid center. The stability of catalyst Mo/HZSM-5 can be improved by steam treatment of the catalyst.

Liu et al (1998) found that addition of $3 \mathrm{vol} \%$ of $\mathrm{CO}_{2}$ into methane could slow down the carbon deposition of the catalyst, and improve the stability of the catalyst. Accordingly, Li et al (2004) proposed combining exothermic reaction of oxidative coupling of methane (OCM) with endothermic reaction of MDA. By such a way, the byproduct $\mathrm{CO}_{2}$ of OCM reaction can be used to improve the stability of catalyst Mo/HZSM-5 for MDA reaction. In a fixed-bed quartz reactor, $0.15 \mathrm{~g}$ OCM catalyst and $1.0 \mathrm{~g}$ MDA catalyst (6 wt \% Mo/HZSM-5 ) were packed in sequence, and under the reaction conditions of feed gas composition of $\mathrm{CH}_{4}: \mathrm{O}_{2}$ : $\mathrm{N}_{2}=9: 0.11: 1$ (molar ratio) and temperature of $730{ }^{\circ} \mathrm{C}$, the methane conversion and the aromatics yield reached $20.1 \%$ and $10.9 \%$, respectively, after $60 \mathrm{~min}$ of reaction, and $15.9 \%$ and $8.9 \%$, respectively, after $960 \mathrm{~min}$ of reaction. While the absence of OCM catalyst and the feed gas composition of $\mathrm{CH}_{4}: \mathrm{N}_{2}=9: 1$ (molar ratio), resulted in methane conversion and aromatics yield being $17.7 \%$ and $12.8 \%$, respectively, after 60 min of reaction, and only $0.9 \%$ and $0.1 \%$, respectively, after $960 \mathrm{~min}$ of reaction. The results indicated that the stability of MDA catalyst was highly improved by combination of OCM and MDA reactions. However, with consideration of commercial application, long-time stability and regeneration of MDA catalyst is still the main challenge to MDA process.

The investigation of catalytic and non-catalytic conversion of methane to methanol and formaldehyde extends over seven decades (Bone, 1931; Hall et al, 1995). However, there is no breakthrough. Methane conversion and methanol selectivity reached $8.1 \%$ and $84.6 \%$, respectively, over 1.7 $\mathrm{wt} \% \mathrm{MoO}_{3} / \mathrm{SiO}_{2}$ catalyst and $\mathrm{N}_{2} \mathrm{O}$ as oxidant at $560{ }^{\circ} \mathrm{C}$ (Liu et al, 1982). When using quartz sands instead of $\mathrm{MoO}_{3} / \mathrm{SiO}_{2}$ catalyst, methane conversion and methanol selectivity reached $8 \%-10 \%$ and $70 \%-80 \%$, respectively, under the conditions of 400-500 ${ }^{\circ} \mathrm{C}, 2.5-6.5 \mathrm{MPa}$, and 2.5-10.0 wt $\% \mathrm{MoO}_{3} / \mathrm{SiO}_{2}$ catalyst and $\mathrm{O}_{2}$ as oxidant (Yarlagadda et al, 1988). Up to date, the above data are the best results of direct catalytic and non-catalytic conversion processes of methane to methanol (Liu et al, 1984). Zhang et al (2004) developed a $7 \mathrm{wt} \%$
$\mathrm{MoO}_{\mathrm{x}} / \mathrm{La}-\mathrm{Co}$ oxide catalyst for methanol synthesis. Under the reaction conditions of $420{ }^{\circ} \mathrm{C}, 4.20 \mathrm{MPa}$, space velocity of $1.44 \mathrm{~L} /(\mathrm{g} \cdot \mathrm{h})$ and a feedstock composition of $\mathrm{CH}_{4}: \mathrm{O}_{2}: \mathrm{N}_{2}=$ 9:1:1(molar ratio), methanol yield and selectivity were $6.7 \%$ and $60 \%$, respectively. Direct selective oxidation of methane to methanol is far away from commercialization. Economic assessment suggests that more than $10 \%$ of per pass methane conversion, and more than $90 \%$ of the sum of methane conversion and methanol selectivity, should be achieved for commercialization of the process (Fould and Gray, 1995).

A new way of conversion of methane to methanol based on liquid mercury sulfate catalyst has been developed by Periana et al (1998). The catalysis cycle includes three main steps:

1. Esterification: $\mathrm{CH}_{4}+2 \mathrm{H}_{2} \mathrm{SO}_{4} \rightarrow \mathrm{CH}_{3} \mathrm{OSO}_{3} \mathrm{H}+2 \mathrm{H}_{2} \mathrm{O}+\mathrm{SO}_{2}$

2. Hydrolyzation: $\mathrm{CH}_{3} \mathrm{OSO}_{3} \mathrm{H}+\mathrm{H}_{2} \mathrm{O} \rightarrow \mathrm{CH}_{3} \mathrm{OH}+\mathrm{H}_{2} \mathrm{SO}_{4}$

3. Re-oxidization: $\mathrm{SO}_{2}+\mathrm{O}_{2}+\mathrm{H}_{2} \mathrm{O} \rightarrow \mathrm{H}_{2} \mathrm{SO}_{4}$

A methane conversion of $50 \%$ and methyl bisulfate selectivity of $85 \%$ is achieved at a temperature of $180{ }^{\circ} \mathrm{C}$. However, the reaction rate of the process is quite slow. $\mathrm{Xu}$ et al (2004b) reported that methane conversion of $72 \%$ and sum selectivity of $\mathrm{CH}_{3} \mathrm{OSO}_{3} \mathrm{H}$ and $\mathrm{CH}_{3} \mathrm{OH}$ of $81 \%$ was achieved under conditions of $220{ }^{\circ} \mathrm{C}, 3.4 \mathrm{MPa}$, reaction time of 2.5 hours, $\mathrm{CH}_{4}$ to catalyst molar ratio of 2.3 and using dichloro( $\eta^{2}-\{2,2$ '-bipyrimydl $\}$ ) platinum (II) complex instead of toxic mercury sulfate. They also reported another system using catalyst $\left(\mathrm{NH}_{3}\right)_{2} \mathrm{PtCl}_{2}$, which is more active than dichloro( $\eta^{2}-\{2,2 '$-bipyrimydl $\}$ ) platinum (II) complex, but less stable. Although low-temperature liquid-phase homogeneous complex catalysis, dichloro- $\left(\eta^{2}-\{2,2\right.$ '-bipyrimydl $\left.\}\right)$ platinum (II), has an advantage of high methanol yield, but the problems of very low reaction rate, requirement of concentrated sulfuric acid, complex product separation, $\mathrm{SO}_{2}$ oxidation and recycle, and free of water during reaction are still the challenge. Thus, conversion of methane to methanol based on this way is not possible for commercialization at present.

Comprehensive investigations on OCM to ethylene have been carried out since 1982 (Lunsford, 2000). Only a few catalysts reach the level that the sum of methane conversion and $\mathrm{C}_{2}$ hydrocarbons selectivity equal to or greater than $100 \% . \mathrm{Na}_{2} \mathrm{WO}_{4}-\mathrm{Mn} / \mathrm{SiO}_{2}$ is still the best catalyst reported for OCM up to date (Li, 2003). Ji and co-works (2004) reported that methane conversion reached $29.5 \%$, ethylene selectivity reached $42.6 \%$ and ethane selectivity reached $23.8 \%$ over $\mathrm{Na}_{2} \mathrm{WO}_{4}-\mathrm{Mn} / \mathrm{SiO}_{2}$ catalyst under conditions of $800{ }^{\circ} \mathrm{C}$, atmospheric pressure, space velocity of 254 $\mathrm{L} /(\mathrm{g} \cdot \mathrm{h})$ and feedstock composition of $\mathrm{CH}_{4}: \mathrm{O}_{2}=3.2: 1$ (molar ratio). Economic assessment suggests that OCM might be commercialized only when per pass methane conversion is more than $30 \%$ and the total $\mathrm{C}_{2}$ hydrocarbons selectivity is more than $80 \%$ (Gradassi and Green, 1995).

\section{Conclusion}

Great progress has been made in indirect natural gas conversion and utilization in the last two decades. Oil and gas 
processes will gradually be unified by integration of hydrogen production, GTL, GTO and oxygenates production processes with refinery and petrochemical processes. Direct natural gas conversion and utilization processes are still in the phase of laboratory research, and opportunities and challenges coexist.

\section{References}

Ashcroft A T, Cheetham A K and Green M L H. Direct catalytic oxidation of methane to synthesis gas. Nature. 1990. 344: 319-320

Bakkerud P K, Gol J N, Aasberg-Petersen K, et al. Preferred synthesis gas production routes for GTL. Studies in Surface Science and Catalysis. 2004. 147: 13-17

Bone W A. Formation of methyl alcohol by direct oxidation of methane over molybdenum oxide supported on silica. Nature. 1931. 127: 481-482

Chen C M, Bennett D L and Carolan M F. ITM syngas ceramic membrane technology for synthesis gas production. Studies in Surface Science and Catalysis. 2004. 147: 55-60

Chen J G and Sun Y H. The structure and reactivity of coprecipitated $\mathrm{Co}-\mathrm{ZrO}_{2}$ catalysts for Fischer-Tropsch synthesis. Studies in Surface Science and Catalysis. 2004. 147: 277-282

Eisenberg B, Fiato R A, Kaufman T G, et al. The Evolution of Advanced Gas-to-Liquids Technology. Chemtech. 1999. 29: 32-38

Fleisch T H and Sills R A. Large-scale gas conversion through oxygenates: Beyond GTL-FT. Studies in Surface Science and Catalysis. 2004. 147: 31-36

Fould G A and Gray B F. Homogeneous gas-phase partial oxidation of methane to methanol and formaldehyde. Fuel Process Technology. 1995. 42: 129-159

Gradassi M J and Green N W. Economics of natural gas conversion processes. Fuel Process Technology. 1995. 42: 65-83

Hall T J, Hargreaves J S J and Hutchings G J. Direct oxidation of methane to methanol and formaldehyde. Fuel Process Technology. 1995. 42: 151-178

Hickman D A and Schmidt L D. Syngas formation by direct catalytic oxidation of methane. Science. 1993. 259: 342-346

Huang L Q, Yuan Y Z and Zhang H B. Dehydro-aromatization of $\mathrm{CH}_{4}$ over W-Mn(or Zn, Ga, Mo, Co)/HZSM-5(or MCM-22) catalysts. Studies in Surface Science and Catalysis. 2004. 147: 565-570

Ji S F, Xiao T C and Li S B. The critical role of the surface $\mathrm{WO}_{4}$ tetrahedron on the performance of $\mathrm{Na}-\mathrm{W}-\mathrm{Mn} / \mathrm{SiO}_{2}$ catalysts for the oxidative coupling of methane. Studies in Surface Science and Catalysis. 2004. 147: 607-612

Kong F H and Wu G J. Present situation and suggestions of Petrochina' s natural gas chemical engineering development. Chemical Engineering of Oil and Gas. 2004. 33(Supplement): 1-4

Li C Y, Yu C C and Shen S K. Studies on the Reasons for Carbon Deposition over $\mathrm{Ni} / \mathrm{Al}_{2} \mathrm{O}_{3}$ Catalyst in partial oxidation of $\mathrm{CH}_{4}$ to syngas with TPO technique. Chinese Journal of Catalysis. 2001. 22(4): 377-382

Li R J, Yu C C, Shen S K, et al. Methane oxidation to synthesized gas using lattice oxygen in $\mathrm{La}_{1-x} \mathrm{Sr}_{\mathrm{x}} \mathrm{FeO}_{3}$ perovskite oxides instead of molecular oxygen. Studies in Surface Science and Catalysis. 2004. 147: 199-204

Li S B. Reaction chemistry of $\mathrm{W}-\mathrm{Mn} / \mathrm{SiO}_{2}$ catalyst for the oxidative coupling of methane. Journal of Natural Gas Chemistry. 2003. 12(1): $1-9$

Li Y G, Liu H M, Xu Y D, et al. Combined single-pass conversion of methane via oxidative coupling and dehydroaromatization: A combination of $\mathrm{La}_{2} \mathrm{O}_{3} / \mathrm{BaO}$ and Mo/HZSM-5 catalysts. Studies in Surface Science and Catalysis. 2004. 147: 583-588

Liu H F, Liu R S, Lunsford J H, et al. Partial oxidation of methane by nitrous oxide over molybdenum on silica. Journal of the American Chemical Society. 1984. 106: 4117-4121

Liu R S, Iwamoto M and Lunsford J H. Partial oxidation of methane by nitrous oxide over molybdenum on silica. Chemical Communications. 1982. 11: 78-79

Liu S L, Dong Q, Ohnishi R and Ichikawa M. Unique promotion effect of $\mathrm{CO}$ and $\mathrm{CO}_{2}$ on the catalytic stability for benzene and naphthalene production from methane on Mo/HZSM-5 catalysts. Chemical Communications. 1998. 11: 1217-1218

Liu Z M, Sun C L, Wang G W, et al. New progress in R\&D of lower olefin synthesis. Fuel Process Technology. 2000. 62(2-3): 161-172

Lu Y, Liu Y and Shen S K. Design of stable Ni catalysts for partial oxidation of methane to syngas. Journal of Catalysis. 1998. 177: 368-388

Lunsford J H. Catalytic conversion of methane to more useful chemicals and fuels: A challenge for the 21 st century. Catalysis Today. 2000. 63: 165-174

Mazanec T J, Prasad R, Odegard R, et al. Oxygen transport membranes for syngas production. Studies in Surface Science and Catalysis. 2001. 136: 147-152

Periana R A, Taube D J, Gamble S, et al. A novel, high yield system for oxidation of methane to methanol. Science. 1998. 280: 560-561

Qi H J, Li D B, Zhong B, et al. Performance of Mn-modified Ni/ $\mathrm{K} / \mathrm{MoS} 2$ catalysts for higher alcohol synthesis. Journal of Fuel Chemistry and Technology. 2003. 31(2): 119-123

Shanxi Institute of Coal Chemistry of Chinese Academy of Sciences. A Methanol Synthesis Route. China Patent, CN 95115889.9. 2000

Shen S K, Pan Z Y and Dong C Y. A novel two-stage process for catalytic oxidation of methane to synthesis gas. Studies in Surface Science and Catalysis. 2001. 136: 99-104

Shu Y Y and Ichikawa M. Catalytic dehydrocondensation of methane towards benzene and naphthalene on transition metal supported zeolite catalysts: Templating role of zeolite micropores and characterization of active metallic sites. Catalysis Today, 2001. 71: 55-67

Wang H H, You C and Yang W S. Investigation of partial oxidation of methane to syngas in a tubular $\mathrm{Ba}_{0.5} \mathrm{Sr}_{0.5} \mathrm{Co}_{0.8} \mathrm{Fe}_{0.2} \mathrm{O}_{3}$ membrane reactor. Catalysis Today. 2003. 82: 157-166

Wang H P. Advances in one-step synthesis of dimethyl ether from syngas. Chinese Industrial Catalysis. 2003. 11(5): 78-82

Wang J F, Ren F, Wang D Z, et al. Research of DME synthesis in slurry reactor by one step process. Chemical Engineering of Oil and Gas. 2004. 33 (Supplement): 42-43

Wang L S, Tao L X, Xie M S, et al. Dehydrogenation and aromatization of methane under non-oxidizing conditions. Catalysis Letters. 1993. 21: $35-41$

Wei W, Sun Y H and Zhong B. Applied fundamental research on supercritical fluids. Journal of Fuel Chemistry and Technology. 1999. 27(Supplement): 41-50

Xie H J, Cui H T, Tan Y S, et al. Research of modified methanol catalyst using in dimethyl ether synthesis by slurry bed reactor. Chemical Engineering of Oil and Gas. 2004. 33 (Supplement): 44-46

Xu X M, Xu H Y, Wang S W, et al. Research of the catalyst used to synthesize dimethyl ether by one-step process. Chemical Engineering of Oil and Gas. 2004a. 33 (Supplement): 58-60

$\mathrm{Xu}$ X, Fua G, Periana R A, et al. Selective oxidation of $\mathrm{CH}_{4}$ to $\mathrm{CH}_{3} \mathrm{OH}$ using the catalytic (bpym) $\mathrm{PtC}_{12}$ Catalyst. Studies in Surface Science and Catalysis. 2004b. 147: 499-504

Xu Y D, Bao X H and Lin L W. Direct conversion of methane under nonoxidative conditions. Journal of Catalysis. 2003. 216: 386-395

Yang Y L, Li W Z and Xu H Y. Influence of $\mathrm{CeO}_{2}$ and $\mathrm{Co}_{3} \mathrm{O}_{4}$ promoters on carbon deposition and carbon elimination over Ni-based catalysts, Chinese Journal of Catalysis. 2002. 23(5): 517-520

Yarlagadda P S, Morton L, Hnuter N R, et al. Direct conversion of 
methane to methanol in a flow reactor. Industrial and Engineering Chemistry Research. 1988. 27: 252-256

Yin $\mathrm{H}$ M. Investigation of $\mathrm{CO}$ hydrogenation on Rh-based catalysts for the synthesis of $\mathrm{C}_{2}$-oxygenates. $\mathrm{PhD}$ Thesis. Dalian Institute of Chemical Physics of Chinese Academy of Sciences. 2003

Yin H M, Ding Y J and Luo H Y. Influence of iron promoter on catalytic properties of $\mathrm{Rh}-\mathrm{Mn}-\mathrm{Li} / \mathrm{SiO}_{2}$ for $\mathrm{CO}$ hydrogenation. Applied Catalysis A. 2003a. 243: 155-164

Yin H M, Ding Y J, Luo H Y, et al. The performance of $\mathrm{C}_{2}$ oxygenates synthesis from syngas over $\mathrm{Rh}-\mathrm{Mn}-\mathrm{Li}-\mathrm{Fe} / \mathrm{SiO}_{2}$ catalysts with various Rh loadings. Energy Fuels. 2003b. 17(6): 1401-1406

Zhang X, He D H, Zhang Q J, et al. Methanol from oxidation of methane over $\mathrm{MoO}_{\mathrm{x}} / \mathrm{La}-\mathrm{Co}$-oxide catalysts. Studies in Surface Science and Catalysis. 2004. 147: 541-546

Zhang Z B, Yu C C and Shen S K. Partial oxidation of $\mathrm{CH}_{4}$ to syngas on $\mathrm{La}_{2} \mathrm{O}_{3}$ promoted $\mathrm{Ni} / \mathrm{MgAl}_{2} \mathrm{O}_{4}$. Chinese Journal of Catalysis. 2000. 21(1): 14-18(in Chinese)

(Edited by Zhu Xiuqin) 